\title{
A ESCOLA E SUA FUNÇÃO SOCIAL: UM OLHAR SOBRE O GÊNERO E A DIVERSIDADE SEXUAL
}

\author{
Renata Quenca Bassan
}

Universidade do Oeste Paulista - UNOESTE, Mestrado em Educação, Presidente Prudente/SP, E-mail: renata.bassan@hotmail.com.

\section{RESUMO}

O presente artigo propõe-se a apresentar uma análise dos desafios enfrentados por alunos LGBT Lésbicas, Gays, Bissexuais, Travestis, Transexuais e Transgêneros nas escolas, tendo como referência principal dois curtas-metragens produzidos pelo Grupo Arco Íris em parceria com a Universidade Federal do Rio de Janeiro - UFRJ que retrata a homofobia e a realidade enfrentada por esses alunos no contexto escolar, se utilizando também de outros artigos e publicações que abordam o tema para dar suporte a análise da pesquisa. A partir da problematização dos curtasmetragens, buscou-se refletir a partir do referencial Pós-Estruturalista sobre a atuação da escola como um dispositivo heteronormativo e reprodutora de discursos sociais que prevalecem na sociedade. A análise dessa pesquisa defende que a escola necessita se adequar aos novos conceitos que emergem na sociedade, valorizando as diferenças e promovendo uma educação transformadora para atingir a sua função social.

Palavras-Chave: escola, diversidade, gênero, heteronormatividade, função social.

\section{THE SCHOOL AND ITS SOCIAL FUNCTION: A VIEW ABOUT GENDER AND SEXUAL DIVERSITY}

\begin{abstract}
This article aims to present an analysis of the challenges faced by LGBT students - Lesbians, Gays, Bisexuals, Transsexuals, Transsexuals and Transgenders in schools, having as main reference two short movies produced by the Arco Íris Group in partnership with the Federal University Of Rio de Janeiro - UFRJ that portrays homophobia and the reality faced by these students in the school context, also using other articles and publications that approach the theme to support the analysis of the research. From the problematization of the short films, we sought to reflect from the PostStructuralist referential on the performance of the school as a heteronormative and reproductive device of social discourses that prevail in society. The analysis of this research argues that the school needs to adapt to the new concepts that emerge in society, valuing the differences and promoting a transformative education to reach its social function.
\end{abstract}

Keywords: school, diversity, genre, heteronormativity, social function. 


\section{INTRODUÇÃO}

Inicia-se essa discussão refletindo sobre a escola, e em como ela pode gerar consequências na vida de um indivíduo. A escola é o local em que as pessoas iniciam a sua vida em sociedade, onde elas experimentam relações e compartilham conhecimentos. É na trajetória escolar que o indivíduo muitas vezes encontra resposta para seus questionamentos e receios, e quando algum aluno possui um sentimento e comportamento diferente daquele que a escola transmite, surge no indivíduo a posição de inferioridade, marginalização, e preconceito.

Atualmente, ainda nos deparamos com escolas que adotam uma perspectiva tradicional, não somente na esfera didática ou pedagógica, mas também na esfera cultural. A dificuldade que a escola apresenta em aceitar a diversidade sexual e de gênero está ligada a uma esfera política e social, motivada por uma visão histórica e cultural construída na trajetória da sociedade, em que as classes dominantes determinavam os padrões de comportamento. As pessoas que seguem uma orientação sexual diferente daquela que impera na sociedade, se tornaram sujeitos hierarquizados a partir de discursos sociais em que a heterossexualidade é o normal, o que chama-se de heteronormatividade. Segundo Louro (2011) "o campo da Educação opera, muito expressivamente, na perspectiva da heteronormatividade - ou seja, dentro da norma heterossexual, quer dizer, no entendimento de que todo mundo é, ou deveria ser, heterossexual."

Com esse padrão de normatividade, a escola acaba legitimando os discursos sociais quando não trata da diversidade e dos respeito às diferenças no ambiente escolar, desencadeando um processo de inferiorização. Nesse sentido, Perrenoud (2000) salienta:

[...]Se um jovem sai de uma escola obrigatória persuadido de que as moças, os negros ou os muçulmanos são categorias inferiores, pouco importa que saiba gramática, álgebra ou uma língua estrangeira. A escola terá falhado drasticamente [...] PERRENOUD (2000 apud JUNQUEIRA, 2009, p. 209)

A diversidade sexual e de gênero ainda se torna um desafio para a escola, que deveria se propor a trabalhar essas relações no ambiente escolar tanto com alunos quanto com professores como forma de combater a desigualdade e promover o respeito às diferenças. Mesmo sendo uma realidade no dia a dia escolar, ainda existe resistência em trabalhar essas questões por ainda prevalecer em nossa sociedade os discursos dominantes.

Buscar uma pedagogia diferente, em que a escola forneça meios para que o aluno construa a sua própria personalidade, identidade e senso crítico, gera tensão e repúdio por parte dos conservadores que ainda acreditam que o diferente é o anormal. Ainda vivemos em um mundo em que a grande parcela da sociedade acredita que a mulher, por ser mulher, não pode fazer tarefas e participar de brincadeiras consideradas de homem, e que homens não podem fazer tarefas e participar de brincadeiras consideradas de mulheres, assim como a pessoa não pode escolher uma identidade de gênero diferente daquela que nasceu com ela, dificultando assim o processo de construção e aprendizado das pessoas.

O objetivo desse artigo é levantar aspectos de reflexão sobre a escola em relação a diversidade sexual e de gênero a partir do referencial Pós Estruturalista, buscando demonstrar através dos curtas-metragens fatores que podem influenciar de forma negativa o processo de desenvolvimento e aprendizado dos alunos LGBT no ambiente escolar. Busca ainda enfatizar que a função social da escola está intimamente ligada ao modo que ela socializa o conhecimento e agrega as pessoas no ambiente de ensino, podendo estreitar as relações ou provocar a desigualdade.

Procedimentos metodológicos:

O método de investigação desse trabalho terá como base principal um recurso audiovisual, tendo como referência dois curtas-metragens intitulados "Novamente" e "Por Outros Olhos", que 
tratam-se de duas produções promovidas e organizadas pelo Grupo Arco Íris em parceria com a Universidade Federal do Rio de Janeiro - UFRJ que visa retratar a homofobia na escola, buscando representar a realidade que os alunos LGBT vivem no ambiente escolar.

Para a escolha dos curtas foi realizada uma pesquisa na internet sobre vídeos que pudessem retratar a temática de forma dinâmica e que abordasse o contexto da realidade vivenciada por esses alunos, de forma que fosse possível uma problematização a partir do conteúdo apresentado. A partir disso, a pesquisa motivou a escolha dos curtas "Novamente" e "Por Outros Olhos" que se deu em função da seriedade e criatividade com que trabalharam o tema Sexualidade, Gênero e Diversidade na escola. Os curtas-metragens tiveram origem a partir de um Projeto denominado "Diversidade Sexual na Escola" que já vinha sendo desenvolvido pela Universidade Federal do Rio de Janeiro, demonstrando experiência e preocupação dos envolvidos em abordar a realidade enfrentada pelos alunos LGBT no ambiente escolar. Além disso, o presente trabalho ainda se utilizou de artigos e demais publicações para aprofundamento no tema.

Discussão:

Ignorar a diversidade sexual e de gênero na escola causa descontentamento e desmotivação de alunos no ambiente escolar, pois enxergam na escola um ambiente de desigualdade. Quando a escola não promove discussão sobre essa temática, intensifica a homofobia no ambiente de ensino, que é a aversão ou repulsa pela homossexualidade. Embora os direitos humanos tenha avançado em nossa sociedade, muitas vezes esses temas não são abordados de maneira adequada no ambiente de ensino, ou muitas vezes, os profissionais da educação não são preparados e incentivados para isso. Destaca Duarte (2015):

O silenciamento em relação à sexualidade no ambiente escolar, em especial na educação infantil, ocorre e torna-se comum por temer-se que, ao abordar tais temáticas, se suscitem mais curiosidades, e, quem sabe, até desperte interesses semelhantes que incidam sobre o paradigma sexualidade. Poderia, ainda encorajar, "determinadas práticas" não coadunadas com a expectativa heteronormativa. (DUARTE, 2015, p. 76)

Um dos receios da escola é justamente trabalhar essa temática no ambiente de ensino e provocar sentimentos indesejáveis para os padrões heteronormativos.

O Curta metragem "Novamente" retrata a vida de jovens no ambiente escolar, sendo um grupo de alunos heterossexuais e um casal homossexual. Os alunos homossexuais sofrem preconceito dos demais ao aparecem juntos na escola, sendo abordados com palavras preconceituosas e condutas violentas.

O vídeo deixa claro a imagem que a escola transmite ao ignorar a questão do gênero e da sexualidade, e isso é retratado no momento em que o aluno homossexual sofre o preconceito e destaca que vai conversar com a inspetora ou diretora para resolver o problema, e seu amigo ironicamente diz: "[...] falar com inspetora ou diretora? vai adiantar alguma coisa? Vai mudar alguma coisa? [..]" e o aluno homossexual conclui: "[...] então eu vou sair do colégio [..]".

O momento vivenciado por esses jovens retrata o que muitos passam na realidade escolar, demonstrando que a escola não está trabalhando adequadamente as relações de convívio. $E$ muitas vezes, caso esteja, a escola não acompanha se as ações estão tendo o impacto desejado. A escola tem como função social humanizar as pessoas e proporcionar instrumentos para que ela consiga construir a sua própria identidade, respeitando às diferenças.

Acerca da função social da escola, Graciani (2015) em sua dissertação de Mestrado, buscou conceituar a função social da escola a partir de teóricos que refletiram sobre o tema, e ao citar pesquisadores e estudiosos como José Carlos Libâneo, João Ferreira de Oliveira e Mirza Seabra Toshi, esclareceu que "a provocação é fazer do ambiente escolar um meio que favoreça o aprendizado, onde a escola deixe de ser apenas um ponto de encontro, e passe a ser, além disso, 
espaço de compartilhar saberes, um ambiente para descobertas de forma prazerosa e funcional". (2015, p. 55). Essa perspectiva nos faz refletir, que infelizmente, o espaço escolar não está cumprindo a contento sua função social, e essa realidade é muito bem retratada nos vídeos citados neste trabalho. Cabe destacar, que se a sociedade age, em sua maioria, de forma preconceituosa e homofóbica, é por influência de um contexto político, social e cultural, que muitas vezes é transmitido pela escola.

O curta-metragem "Por outros olhos" retrata a vida de um casal jovem heterossexual que sofre preconceito dos demais alunos que são homossexuais, abordando o mundo ao contrário, em que o homossexualismo é considerado normal e o heterossexualismo é considerado anormal, demonstrando o preconceito e a violência que os alunos LGBT (Lésbicas, Gays, Bissexuais e Travestis) passam na vida real.

O vídeo demonstra que a homofobia estava presente nos colegas da escola e nos pais, e que para obter aceitação das pessoas, eles precisavam se passar por homossexuais para não sofrerem preconceito na escola, vivenciando a infelicidade e o medo.

Tratar de uma pedagogia transformadora com novos olhares e novas metodologias ainda causa instabilidade no ambiente escolar, pois surge um confronto de sexualidade que para a escola não é o desejado. Para Bourdieu (2002 apud JÚNIOR, 2015, p 06.) a escola não apenas transmite e constrói conhecimento, mas também reproduz padrões sociais, perpetuando valores e fabricando sujeitos. Nesse sentido, a escola se torna um dispositivo de normatividade da sexualidade, um elemento dominador das relações de poder e de doutrinamento. César (2009) explica que:

[...] a presença da sexualidade na escola pode perfeitamente se traduzir na função de reproduzir o dispositivo de controle dos corpos, assim como em paradigma biopolítico de controle da vida, pois foi justamente na instituição escolar que se instauraram historicamente os dispositivos disciplinares e de governamento sobre os corpos de crianças e jovens. (CÉSAR, 2009, p. 44)

A escola precisa aceitar que as pessoas não podem ser tratadas de forma generalizada e a partir de discursos normativos que servem para alguns mas não servem para outros. As pessoas se transformam e novos conceitos e possibilidades emergem em nossa sociedade, e a escola precisa caminhar nessa perspectiva. De acordo com Louro (2012):

Ao aceitarmos que a construção do gênero é histórica e se faz incessantemente, estamos entendendo que as relações entre homens e mulheres, os discursos e as representações dessas relações estão em constante mudança. Isso supõe que as identidades de gênero estão continuamente se transformando. [...] (LOURO, 2012, p. 39)

Ao refletir sobre as diferenças culturais, cotidiano escolar e práticas pedagógicas, Candau (2011) destaca que:

As diferenças culturais - étnicas, de gênero, orientação sexual, religiosas, entre outras [...] No âmbito da educação também se explicitam cada vez com maior força e desafiam visões e práticas profundamente arraigadas no cotidiano escolar. A cultura escolar dominante em nossas instituições educativas, construída fundamentalmente a partir da matriz político-social e epistemológica da modernidade, prioriza o comum, o uniforme, o homogêneo, considerados como elementos constitutivos do universal. Nesta ótica, as diferenças são ignoradas ou consideradas um "problema" a resolver. (CANDAU, 2011, p. 02) 
Essa falha que ocorre no processo escolar provoca a exclusão e discriminação desses alunos, que acabam se afastando da escola ou começam a desenvolver um sentimento de repulsa e constrangimento.

Conclusão:

Através dos curtas-metragens foi possível refletir acerca da realidade escolar sob o olhar dos alunos LGBT, estando claro que a escola ainda precisa avançar historicamente e culturalmente para abrir espaço para um novo olhar na educação. Por mais que tenhamos pedagogias diferenciadas e críticas que se opõem a visão tradicional, sabemos que a maior parte das escolas ainda atuam em uma perspectiva normativa, refletida em todos os sujeitos do ambiente escolar.

A crítica transmitida pelos curtas não envolve somente rotina e valores, mas esclarece a condição de vida que esses alunos vivem no ambiente escolar, demonstrando que esses sujeitos vivem à margem da sociedade e sem muita perspectiva de melhorar a sua condição naquele contexto.

O fator principal que se vê refletido nos curtas-metragens é a heteronormatividade, que se trata de um elemento utilizado como verdade absoluta na sociedade, retratando as relações de dominação que perpassam o gênero, a sexualidade, e também a raça e a etnia. É nesse sentido que a perspectiva Pós Estruturalista tem como missão descontruir essa verdade absoluta, criando mecanismos de questionamento desse discurso dominante. Segundo estudos de Judith Butler (1999) interpretados por Aguilar e Gonçalves (2017), a heterossexualidade compulsória ou heteronormatividade é o conceito que foi construído culturalmente e visto como o único aceitável em diversos grupos sociais, sendo necessário romper com esses preceitos, a fim de que se respeitem as diferentes identidades de gênero e sexuais.

A escola, vista muitas vezes como um elemento doutrinador, ainda encara a presença de alunos LGBT como algo ameaçador, pois o tradicional ainda é presente na maioria das escolas, e por esse motivo é difícil rompermos com certos paradigmas e avançarmos com novos olhares e metodologias na educação. Por conta dessa ordem social que ainda impera nas escolas, os alunos LGBT vivem constrangidos quando se assumem definitivamente, passando a não ter mais interesse em fazer parte do ambiente escolar.

Esse constrangimento vivenciado pelos alunos LGBT tem destaque nos curtas-metragens quando os alunos se sentem constrangidos e marginalizados ao conviver no espaço escolar com os demais. O tratamento que recebem dos colegas reflete esse discurso reprodutor e dominante transmitido pela escola.

A cultura da nossa sociedade ainda está enraizada nos discursos dominantes, e quebrar com esse paradigma ainda é uma tarefa árdua para nós educadores e pesquisadores, que temos que continuar lutando por uma escola transformadora e acolhedora, e que acime de tudo acompanhe e encare as necessidades e os acontecimentos de sua época para contribuir de fato com a sociedade. Segundo Hall (1999 apud FLEURI p. 2003), as sociedades modernas não têm nenhum núcleo identitário supostamente fixo, coerente e estável. Por isso, a escola necessita se adequar às transformações que ocorrem no seu momento histórico para que consiga cumprir com a sua função social, promovendo a igualdade e contribuindo para a formação do sujeito crítico e reflexivo.

\section{REFERÊNCIAS:}

AGUILAR, Márcia Adriana Brasil; GONÇALVES, Josiane Peres. Conhecendo a perspectiva pósestruturalista: breve percurso de sua história e propostas. Conhecimento Online, v. 1, p. 36-44, 2017. Disponível em: <http://periodicos.feevale.br/seer/index.php/revistaconhecimentoonline/article/viewFile/460/18 52> Acesso em: 25 agosto 2017. 
CANDAU, Vera Maria Ferrão. Diferenças culturais, cotidiano escolar e práticas pedagógicas. Currículo sem fronteiras. 2011. Disponível em: <http://www.curriculosemfronteiras.org/vol11iss2articles/candau.pdf> Acesso em: 05 junho de 2017.

CÉSAR, Maria Rita de Assis. Gênero, sexualidade, e educação: notas para uma epistemologia. Educar, Curitiba, no 35, p. 37-51, 2009.

Pensar a educação depois de Focault. Cult. Disponível em <https://revistacult.uol.com.br/home/pensar-a-educacao-depois-de-foucault/.> Acesso em: 30 maio 2017.

DUARTE, Maria L. T. Escola: lugar político da diversidade sexual e de gênero. 2015, 235f. Tese (Doutorado em Ciências Sociais), Universidade Federal do Rio Grande do Norte, 2015.

FLEURI, Reinaldo Matias. Intercultura e educação. Disponível em: http://www.scielo.br/pdf/rbedu/n23/n23a02. Acesso em 25 de Junho de 2017.

LOURO, Guacira Lopes. Educação e docência: diversidade, gênero e sexualidade. Disponível em <http://formacaodocente.autenticaeditora.com.br/artigo/exibir/9/30/1> Acesso em 29 de Maio de 2017

GRACIANI, Graziela Dantas. A função social da escola pública brasileira: um estudo exploratório. 2015, 191f. Dissertação (Mestrado em Educação), Universidade de São Paulo - USP, 2015.

JUNQUEIRA, Rogério Diniz. Currículo heteronormativo e cotidiano escolar homofóbico. ESPAÇO DO CURRÍCULO, v.2, n.2, pp.208-230, 2010.

JUNIOR, Ednildon R. F. Homofobia e Heterossexismo nas Escolas: Propostas Pedagógicas Inclusivas. XI Colóquio Nacional de Gênero e Sexualidade da Universidade Federal do Paraíba, Editora Realize, 2015, 14 p.

PELÚCIO, Larrisa. Subalterno quem, cara pálida? Apntamentos ás margens sobre póscolonialismos, feminismos e estudos queer. Contemporânia, São Carlos, v.2, n.2, p. 395-418, 2012. Disponível em: <http://www.contemporanea.ufscar.br/index.php/contemporanea/article/viewFile/89/54> Acesso em: 13 junho 2017. 